DOI: $10.34220 /$ issn.2222-7962/2020.2/17

УДК674.09:630.812

РАЦИОНАЛЬНОЕ ИСПОЛЬЗОВАНИЕ ДРЕВЕСИНЫ ДУБА МОРЕНОГО И НАТУРАЛЬНОГО

\author{
кандидат технических наук, доцент Т.К. Курьянова ${ }^{1}$ \\ директор ФГБУ «Воронежский государственный заповедник» А.А. Тарасов² \\ доктор технических наук, доцент А.Д. Платонов ${ }^{1}$ \\ кандидат биологических наук, доцент С.Н. Снегирева ${ }^{1}$
}

1 - ФГБОУ ВО «Воронежский государственный лесотехнический университет имени Г.Ф. Морозова»,

г. Воронеж, Российская Федерация

2 - ФГБУ «Воронежский государственный природный биосферный заповедник имени В.М. Пескова»,

г. Воронеж, Российская Федерация

Древесина дуба мореного - ценный и один из самых экологически чистых натуральных природных материалов. В результате длительного нахождения древесины в проточной речной воде и в контакте с донным грунтом без доступа воздуха происходит индивидуальный процесс морения каждого ствола, заключающийся в изменении химического состава древесины. Древесина приобретает повышенную прочность и красивую цветовую гамму. Установлено, что степень окраски древесины дуба мореного зависит от количества в нем оксидов железа $\left(\mathrm{Fe}_{2} \mathrm{O}_{3}\right)$. На территории РФ имеются промышленные запасы этой древесины. Одной из ключевых технологических операций является процесс сушки. Наиболее распространенные способы сушки древесины дуба мореного - конвективно-атмосферная и конвективно-тепловая - отличаются большой продолжительностью, а количество брака по короблению и растрескиванию достигает 30-40 \%. В работе исследована усушка древесины дуба мореного высушенного различными способами. Установлено, что усушка древесины дуба мореного больше, чем древесины дуба натурального в 1,5-2,0 раза. Предварительная термохимическая обработка позволяет уменьшить величину объемной усушки древесины на $25 \%$. Выполнен анализ изменения окраски древесины дуба мореного в зависимости от условий морения древесины в р. Воронеж. Определение качества и величины усушки древесины дуба мореного, высушенного различными способами, необходимо для обоснования припусков при получении размеров пиломатериалов при раскрое круглого леса. Выполненные исследования позволят рационально и эффективно использовать ценную и уникальную древесину дуба.

Ключевые слова: древесина дуба мореного, продолжительность сушки, усушка, термохимическая обработка древесины, качество сушки, цвет древесины

\title{
RATIONAL USE OF FUMED AND NATURAL OAK WOOD
}

\author{
$\mathrm{PhD}$ (Engineering), Associate Professor T.K. Kuryanova ${ }^{\mathbf{1}}$ \\ Head of the FSBI Voronezh State Reserve A.A. Tarasov ${ }^{2}$ \\ DSc (Engineering), Associate Professor A.D. Platonov ${ }^{1}$ \\ PhD (Biology), Associate Professor S.N. Snegireva ${ }^{1}$ \\ 1 - FSBEI HE "Voronezh State University of Forestry and Technologies named after G.F. Morozov", \\ Voronezh, Russian Federation \\ 2 - FSBI Voronezh State Nature Biosphere Reserve named after V.M. Peskov, \\ Voronezh, Russian Federation
}

\begin{abstract}
Fumed oak wood is valuable and one of the most environmentally friendly natural materials. As a result of a long stay of wood in flowing river water and in contact with bottom soil without air access, an individual process of
\end{abstract}




\section{Деревопереработка. Химические технологии}

staining of each trunk occurs. It consists in changing the chemical composition of the wood. The wood acquires increased strength and a beautiful color scheme. It is established that the degree of coloring of fumed oak wood depends on the amount of iron oxides in it $\left(\mathrm{Fe}_{2} \mathrm{O}_{3}\right)$. There are industrial stocks of this wood in the Russian Federation. Drying process is one of the key technological operations. The most common methods of fumed oak wood drying are convective-atmospheric and convective-thermal ones. They have long duration, and the number of defects in warping and cracking reaches $30-40 \%$. In this work, the drying of fumed oak wood by various methods has been investigated. It has been established that shrinkage of fumed oak wood is 1.5-2.0 times more than of natural oak woo. Preliminary thermochemical treatment enables to reduce the volumetric shrinkage of wood by $25 \%$. An analysis of the color change of fumed oak wood depending on the conditions of wood staining in the river Voronezh has been made. Determination of the shrinkage quality and size is necessary to justify the allowances for obtaining sizes of lumber when cutting round wood. The studies performed will allow the rational and efficient use of valuable and unique oak wood.

Keywords: fumed oak wood, drying time, shrinkage, thermochemical processing of wood, drying quality, wood color

\section{Введение}

Наиболее ценный и труднодоступный из всего древесного материала, созданного природой на протяжении многих столетий и тысячелетий, мореный дуб. Из всех натуральных природных материалов древесина дуба мореного является самой экологически чистой. Запасы мореного дуба ограничены и невосполнимы. Каждый ствол мореного дуба прошел свой индивидуальный многовековой путь. Поэтому каждый экземпляр неповторим и уникален. Истинная стоимость пиломатериалов из древесины дуба мореного на порядок выше самых дорогих пиломатериалов из всех созданных природой.

Дуб мореный - это уникальное дерево, которое прожило на Земле две жизни: растительную, наполненную энергией роста под действием солнца, воздуха, воды, почвы, и скрытую, без воздействия солнца и без доступа кислорода - жизнь под водой.

Эта вторая жизнь началась много веков назад. Вследствие размыва берегов и изменения русла рек, деревья прибрежных дубовых рощ падали в воду, при сплавах, при намеренном затоплении и по другим причинам древесина оказалась под водой на дне водоемов. Нахождение древесины в течение многих сотен и тысяч лет в проточной речной воде и в контакте с донным грунтом без доступа воздуха в практике называется морением.

При морении в древесине происходит изменение химического состава. Из клеточных стенок гидролизуются и вымываются наиболее нестойкие структурные элементы - главным образом, геми- целлюлозы. Они вымываются, а их место занимают соли металлов - железа, алюминия и т. д. При более длительном нахождении ствола дерева в воде происходит минерализация основного структурного элемента - целлюлозы. При этом усиливаются межструктурные связи, и древесина становится более прочной, плотной, твердой по сравнению с натуральной древесиной.

В процессе морения древесина дуба, наряду с повышением прочностных свойств, приобретает неповторимую цветовую гамму и очень красивую текстуру.

Окраска древесины дуба мореного подчеркивает красоту текстуры этой породы. В древесине дуба сильно развиты сердцевинные лучи, хорошо видимые на всех разрезах - торцовом, радиальном и тангенциальном. При морении сердцевинные лучи приобретают серебристо-седую с благородным блеском окраску и видны в виде узких и широких полосок и прожилок, что делает текстуру этой древесины неповторимо красивой.

Приобретенные прочностные и декоративные свойства древесины дуба в результате морения делают этот материал редким, уникальным, драгоценным, равного которому в мире нет.

Древесина дуба мореного издавна ценилась во всех странах, а на Руси этот материал - древний, изделия из него передавались по наследству. Использовался этот драгоценный материал в производстве дорогой мебели, высокохудожественных сувениров, музыкальных инструментов, декора, паркета, для отделки салонов, кают пароходов, для создания подлинных произведений искусства и т. д. 
Традиции использования древесины дуба мореного в течение последнего столетия претерпели много испытаний. На территории Европы запасов этой древесины практически не осталось. В России около 70 лет назад использование этого материала почти приостановилось, несмотря на многовековой опыт его добычи и обработки.

В России до революции промышленным способом мореный дуб добывался акционерным обществом «Московско-Рязанская железная дорога». Но с начала Первой мировой войны добыча мореного дуба в России была прекращена. Это связано с тем, что добывающий материал в основном поставлялся в Европу, но из-за войны все контракты были аннулированы.

В настоящее время, в XXI веке - веке прогресса и передовых технологий, древесина дуба мореного представляет исключительный интерес в среде профессионалов-лесопереработчиков и в среде производителей элитных предметов и мебели.

В Российской Федерации возрождение промысла добычи и использования древесины дуба мореного началось в начале 2000-х годов. В 2002 году был создан консорциум «Русэкспорт», который занялся возрождением утраченных технологий добычи, переработки, сушки и производства изделий из древесины дуба мореного. Запасы древесины дуба мореного на территории РФ сохранились благодаря тому, что в течение 70 лет добыча этого материала не велась в промышленных масштабах.

«Сенежская лаборатория защиты древесины» исследовала наличие мореного дуба на территории Мордовии, Ярославской области, в реках Мокше, Суре, Самаре, Черемшане, Мологе, Сож и в реках Московско-Волжско-Окского бассейна. Из отчета лаборатории «Сенеж» получены сведения, что только на реке Мокше и её притоках запасы мореного дуба составили до 2500 стволов с запасом древесины до $3500 \mathrm{~m}^{3}$, по состоянию на 1911/12 г. [1]. По другим сведениям, на реке Мокше запасы намного скромнее, около $1800 \mathrm{~m}^{3}$.

Имеются сведения о достаточно больших запасах мореного дуба в реках Воронежской области - Хопер, Дон, Воронеж, Битюг, Усманка и др.
Только на реке Воронеж в Рамонском районе запасы оценивают в $1500 \mathrm{~m}^{3}$.

Добыча мореного дуба и его обработка очень сложный, длительный процесс, требующий больших трудозатрат и ресурсов. Прежде всего, это сложность поиска и определение состава обнаруженной партии; проблемы подъема стволов на поверхность и их хранения; необходимость индивидуального подхода к каждому поднятому экземпляру.

Каждый ствол мореного дуба, даже из одной партии, имеет свои индивидуальные параметры и существенные отличия, начиная от различий в цветовой гамме и кончая прочностными показателями.

Свойства древесины мореного дуба зависят от качества и размера исходного материала, его макроструктуры, плотности, прочности, ареала произрастания, от химического состава речной проточной воды, наличия и количества в ней солей металлов, особенно железа $\left(\mathrm{Fe}_{2} \mathrm{O}_{3}\right)$, от вида донного грунта - песок или глина, от глубины залегания стволов и продолжительности нахождения их под водой.

Использование древесины дуба мореного, особенно в настоящее время, целесообразно не только из-за красоты изделий из нее, а прежде всего, во имя сохранения живой природы - сохранения дубрав и сбережения ценных пород, в частности дуба.

Дубравы (дубовые леса) имеют огромное значение для сохранения окружающей среды. Основная лесообразующая порода этих лесов - дуб. Он лидирует в полезащитном лесоразведении, влияет на водный режим и структуру почвы, превосходит многие породы по оздоровительному влиянию на окружающую среду, интенсивно выделяя кислород.

В мире насчитывается около 600 видов этой породы, в том числе в РФ произрастает 19 видов дикорастущих и 43 вида выведенных [2].

Древесина дуба характеризуется высокими качественными показателями. Это прочный, твердый, стойкий против гниения, долговечный материал с красивой текстурой, хорошо гнется. Благодаря этим качествам древесина дуба имеет чрезвычайно разнообразное применение. Используется 


\section{Деревопереработка. Химические технологии}

как конструкционный и технологический материал в строительстве, судо- и авиастроении, машиностроении, при изготовлении дорогой мебели, паркета, строганого шпона для отделки изделий, в тарном производстве - главным образом коньячных и винных бочек, в дубильно-экстрактовом производстве и т. Д.

Удовлетворить потребности промышленности в древесине дуба проблематично, так как запасы такой древесины в лесах мира незначительные. Дубовые леса занимают около 1,5 \% от общего объема всех лесов Земли. Но они продолжают деградировать, согласно статистике, каждые 20-30 лет их численность сокращается на 20-30 \%.

Запас древесины дуба в Российской Федерации составляет 0,82 млрд м ${ }^{3}$, это около $1 \%$ от общего объема древесины в лесах России.

В малолесной Воронежской области площадь дубовых лесов составляет 174,1 тыс. га с запасом древесины 1043,1 тыс. м $^{3}$ (по состоянию на 01.01.2014 г.).

Небольшие площади дубрав, незначительный запас древесины дуба, длительный срок его воспроизводства - все это требует защиты дубрав, имеющих огромное природоохранное значение, а также бережного, рационального использования древесины этой ценной породы.

Одним из направлений охраны природы является добыча и использование мореного дуба. Этот промысел не наносит ущерба живой природе, а наоборот, способствует сохранению уникальных дубрав и ценной древесины.

Поднятый на поверхность круглый лес дуба мореного - это нестойкое сырье биологического происхождения, требующее сложной, особой технологии переработки и сушки.

Одной из ключевых технологических операций является процесс сушки. Это наиболее длительный и один из самых трудоемких и дорогих процессов во всей технологии деревообработки, направленный на формирование показателей качества готовой продукции.

Сушка является необходимой и важной технологической операцией. В результате сушки сырая древесина дуба мореного превращается в промышленную продукцию - ценный, дорогой конст- рукционный, поделочный материал с рядом уникальных свойств.

Существующие наиболее распространенные способы сушки древесины дуба мореного - конвективно-атмосферная и конвективно-тепловая - отличаются большой продолжительностью. Количество брака древесины дуба мореного, высушенного этими способами, по короблению, растрескиванию достигает 30-40\%.

Интенсифицировать процесс сушки можно повысив газопроницаемость структуры древесины за счет предварительной термообработки повышенной температурой $140-190{ }^{\circ} \mathrm{C}$ в течение 3-5 часов [3]. Такой способ обработки снижает прочностные свойства древесины. Интенсифицировать процесс сушки и снизить растрескивание древесины трудносохнущих пород возможно путем ее предварительной термохимической обработки растворами гигроскопических веществ [4]. В результате такой обработки соляной раствор позволяет избежать чрезмерного пересыхания поверхности, снизить усушку материала, предохранить его от растрескивания [5].

Наряду с формированием качества готовой продукции при сушке изменяются размеры древесины - происходит её усушка. Величина усушки зависит от многих факторов: от температурновлажностного воздействия на древесину, от анизотропии усушки, вида пиломатериала. Усушка способствует развитию покорбленности и растрескиванию древесины, что нарушает её формоустойчивость $[6,7]$. Исследованию влияния анатомического строения древесины и способа обработки на величину усадки и развитие коллапса некоторых пород древесины посвящены работы ученых [8-11]. Зависимость усушки от размерно-качест-венных характеристик пиломатериалов после камерной сушки рассмотрена в работах $[9,12]$. Исследованию некоторых свойств и качества древесины дуба мореного посвящены работы ученых [9, 13-17].

В результате исследования установлено, что усушка древесины дуба мореного значительно выше усушки древесины дуба натурального, в среднем в 1,5-2,0 раза.

Представленные в литературе сведения не в полной мере отражают свойства, качество и усушку 
древесины дуба мореного и требуют проведения дополнительных исследований.

\section{Методика проведения исследований}

Для проведения исследований была взята древесина дуба натурального, произрастающего на территории Воронежской области, и древесина дуба мореного из р. Воронеж. Средняя начальная влажность круглого лесоматериала у натуральной древесины дуба была 56 \%, у древесины дуба мореного - $105 \%$. Затем из древесины были выпилены пиломатериалы толщиной 35 мм. Часть пиломатериалов была подвергнута термохимической обработке раствором хлорида натрия при температуре кипения в течение 2,5 часов. Глубина пропитки зависит от начальной влажности древесины и ее структуры и во всех опытах не превышала 1 мм.

Атмосферная сушка всех пиломатериалов из натуральной и мореной древесины дуба проводилась при температуре окружающей среды $22 \ldots 26{ }^{\circ} \mathrm{C}$ и относительной влажности воздуха $0,45 \ldots 0,65$. Месяц укладки - май. Часть образцов из натуральной и мореной древесины дуба высушивали до конечной влажности 12 \% для определения продолжительности сушки в зависимости от способа обработки. Часть пиломатериалов из натуральной и мореной древесины дуба высушивали до влажности 35 \% для определения величины усушки в зависимости от способа обработки.

После достижения древесиной влажности $35 \%$ из пиломатериалов были изготовлены малые чистые образцы для определения усушки. Усушка древесины была определена согласно ГОСТ 16483.37-88 «Древесина. Методы определения усушки». Минимальное количество образцов принято согласно ГОСТ 16483.0-89, СТ СЭВ 6470-88 «Древесина. Общие требования к физико-механическим испытаниям».

\section{Результаты исследований}

В химическом составе древесины дуба присутствуют экстрактивные дубильные вещества (гидролизуемые таниды). При нахождении древесины дуба в воде дубильные вещества окисляются солями металлов, проявляют свою окраску и окрашивают древесину дуба в широкую гамму оттенков от светло-коричневого до угольно-черного с фио- летовым отливом. На рис. 1 представлена окраска древесины дуба мореного из р. Воронеж по сравнению с древесиной дуба натурального.

Степень окраски древесины дуба мореного зависит от количества в нем оксидов железа $\left(\mathrm{Fe}_{2} \mathrm{O}_{3}\right)$. Содержание оксидов железа определялось в древесине дуба мореного из р. Воронеж. В составе мореной древесины желтого цвета содержание оксидов железа составило 5,5\% (рис. 1, поз. 4) и $68,1 \%$ (рис. 1, поз. 1) в мореной древесине черного цвета, натуральная древесина дуба содержит 3,8 \% (рис. 1, поз. 5) [18]. Древесина черного цвета очень плотная и прочная, и её часто называют железным деревом. Такую неповторимую окраску приобретает только древесина дуба.

Изменение окраски древесины дуба мореного является важнейшим декоративным фактором и косвенным показателем продолжительности нахождения древесины под водой $[16,17]$.

Существующие способы сушки длительны по продолжительности и не обеспечивают высокого качества высушенной древесины дуба мореного. В настоящее время проводятся исследования по разработке способов сушки, позволяющих значительно сократить продолжительность сушки древесины дуба мореного, а также повысить качество высушиваемой древесины $[4,5,18]$.

Результаты исследования атмосферной сушки древесины дуба натурального и мореного представлены в табл. 1.

Анализ результатов атмосферной сушки показывает, что на продолжительность сушки влияет способ обработки. Продолжительность сушки пиломатериалов после термохимической обработки сократилась у натуральной древесины в 2,8 раза, у мореной древесины дуба - в 3,9 раза. На торце пиломатериалов необработанной древесины появились трещины и покоробленность. На торце древесины после термохимической обработки отмечены единичные мелкие трещины.

Результаты исследования усушки древесины дуба мореного и натурального представлены на рис. 2. 


\section{Деревопереработка. Химические технологии}

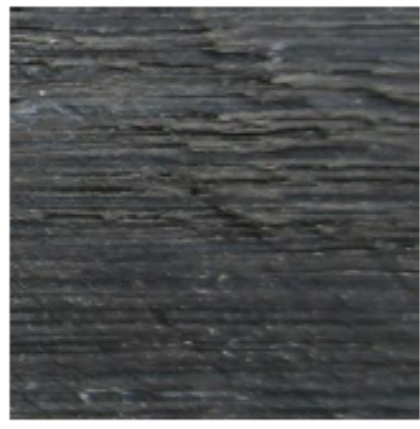

1

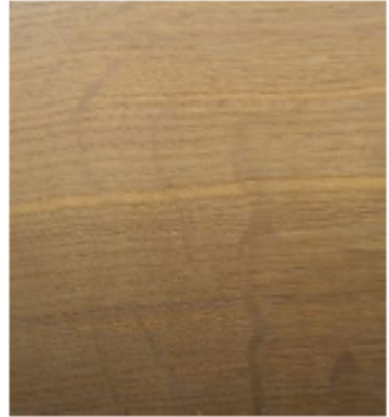

4

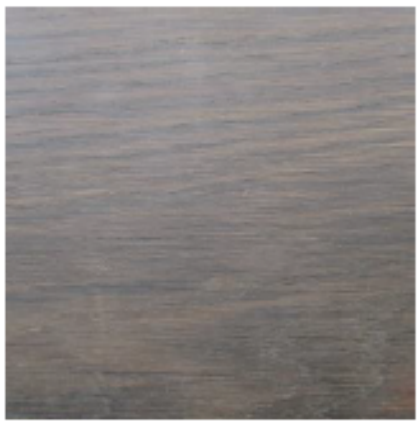

2

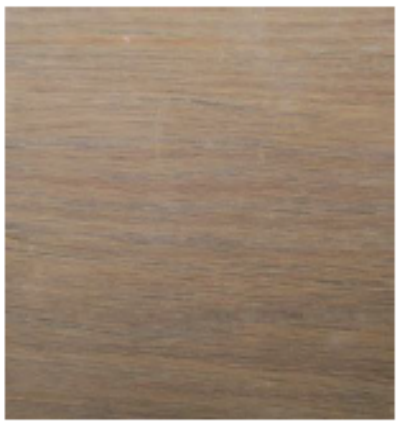

3

Рис. 1. Окраска древесины дуба мореного и натурального:

1, 2, 3,4 - мореная древесина дуба - черная, темно-коричневая, коричневая, светло-коричневая;

5 - натуральная древесина

Источник: собственное фото авторов

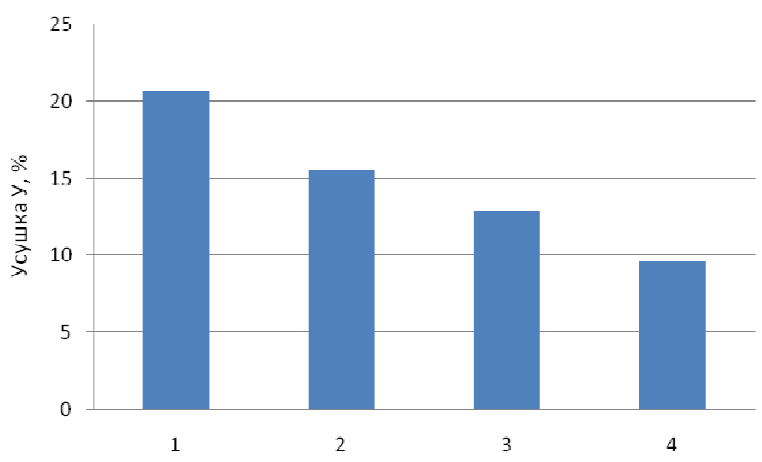

Рис. 2. Объёмная усушка древесины дуба мореного и натурального:

1 - мореная; 2 - мореная термохимически обработанная; 3 - натуральная; 4 - натуральная термохимически обработанная

Источник: собственные вычисления авторов

Анализ результатов экспериментальных исследований, представленных на рис. 2, показывает, что объёмная усушка древесины дуба мореного из p. Воронеж составила 20,7 \%, а дуба натурального 12,9 \%. Величина усушки дуба мореного больше, чем у древесины дуба натурального, на 60,4 \%.
После термохимической обработки величина объёмной усушки соответственно составила 15,6 \% и 9,6\%. После термохимической обработки величина усушки дуба мореного больше, чем у древесины дуба натурального, на 61,5\%.

Лесотехнический журнал $2 / 2020$ 
Способ термохимической обработки древесины дуба мореного и натурального уменьшает величину усушки на $25 \%$.

Усушка древесины дуба мореного зависит от места произрастания исходного сырья и условий морения. Так, например, объемная усушка древесины дуба мореного черного цвета из реки Воронеж составила 20,7 \%, а из реки Сош (Республика Беларусь) - 14,7 \%.

При раскрое круглого леса на пиломатериалы назначаются припуски на усушку для получения размеров, соответствующих ГОСТу. Припуски на усушку разработаны только для древесины дуба натурального. Для древесины дуба мореного эти данные отсутствуют.

\section{Выводы}

Анализ литературных данных показывает, что свойства и качество древесины дуба мореного исследованы недостаточно.

Изменение окраски древесины дуба мореного является важнейшим декоративным фактором и косвенным показателем продолжительности нахо- ждения древесины под водой и может быть использовано как диагностический признак оценки качества древесины дуба мореного.

Исследования усушки древесины дуба мореного, высушенного различными способами, необходимы для обоснования припусков на усушку при раскрое круглого леса.

Предварительная термохимическая обработка древесины дуба мореного и натурального уменьшает величину объемной усушки на $25 \%$.

Исследования по влиянию термохимической обработки на качество и величину усушки древесины дуба мореного актуальны. Результаты этих исследований обеспечат рациональное и эффективное использование ценной и уникальной древесины дуба мореного. Использование древесины дуба мореного имеет большое природоохранное значение, так как способствует сохранению дубовых лесов.

Продолжительность атмосферной сушки пиломатериалов трудносохнущих пород до 12 \%

в IV климатической зоне (месяц укладки - май)

\begin{tabular}{|c|c|c|c|c|c|c|}
\hline \multirow[t]{3}{*}{ Порода } & \multirow{3}{*}{$\begin{array}{c}\text { Толщина } \\
\text { пиломате- } \\
\text { риала } \\
\text { h, мм }\end{array}$} & \multirow{3}{*}{$\begin{array}{c}\text { Начальная } \\
\text { влажность } \\
\text { W, \% }\end{array}$} & \multicolumn{4}{|c|}{ Продолжительность сушки пиломатериалов $\tau$, сут. } \\
\hline & & & \multicolumn{2}{|c|}{$\begin{array}{c}\text { без химической } \\
\text { обработки }\end{array}$} & \multicolumn{2}{|c|}{$\begin{array}{c}\text { после химической } \\
\text { обработки }\end{array}$} \\
\hline & & & $\begin{array}{c}\text { Время } \\
\text { сушки } \tau, \\
\text { сут }\end{array}$ & $\begin{array}{c}\text { Конечная } \\
\text { влажность } \\
\text { к }, \%\end{array}$ & $\begin{array}{c}\text { Время } \\
\text { сушки } \tau \text {, } \\
\text { сут }\end{array}$ & $\begin{array}{c}\text { Конечная } \\
\text { влажность } \mathrm{W}_{\mathrm{\kappa}}, \%\end{array}$ \\
\hline Дуб & 35 & 56 & 142 & 11,4 & 50 & 11,3 \\
\hline Дуб мореный & 35 & 105 & 168 & 11,6 & 43 & 11,2 \\
\hline
\end{tabular}

Источник: собственные вычисления

Библиографический список

1. Разработка упрощенной технологии хранения кругляка и атмосферной сушки пиломатериалов мореного дуба / Отчет по НИР. - Москва : НПП «Сенеж», 1985. - 48 с.

2. Качалов, А. А. Деревья и кустарники : справ. / А. А. Качалов ; под ред. проф. А. И. Колесникова. Москва : Лесная промышленность, 1970. - 408 с.

3. Jang, E. Changes in gas permeability and pore structure of wood under heat treating temperature conditions / E. Jang, C. Kang // J. Wood Sci. - 2019. - No. 65. - P. 37. - DOI: https://doi.org/10.1186/s10086-019-1815-3.

4. Пат. № 2009703 Российская Федерация, МПКㄱ 5 B 01 D 53/34. Способ сушки древесины дуба мореного / Т. К. Курьянова, А. Д. Платонов, Н. К. Тихонов, А. В. Зюзин, О.В. Аралова ; заявитель и патентообладатель ООО НПФ «Инно Тех». - № 2007124993/06 ; заявл. 02.07.2007 ; опубл. 27.03.2009. - 4 с. 


\section{Деревопереработка. Химические технологии}

5. Платонов, А. Д. Интенсификация процесса сушки древесины трудносохнущих пород : специальность 05.21 .05 «Древесиноведение, технология и оборудование деревообработки» : дис. ... д-ра техн. наук : защищена 28.04.2006 / Платонов Алексей Дмитриевич. - Воронеж: ВГЛТА, 2006. - 280 с.

6. Kang, W., Relationship between radial variations in shrinkage and drying defects of tree disks / W. Kang, N. Lee // J. Wood Sci. - 2004. - No. 50. - P. 209-216. - DOI: https://doi.org/10.1007/s10086-003-0559-1.

7. Longitudinal shrinkage variations within trees of sugi (Cryptomeria japonica) cultivars / K. Yamashita, Y. Hirakawa, H. Nakatani [et al.] // J. Wood Sci. - 2009. - No. 55. - P. 1-7. - DOI: https://doi.org/10.1007/s10086008-0987-z.

8. Kollman, F. Technologie des holses und der Terlin erkstoff / F. Kollman. - Berlin, 1955. - 1183 p.

9. Курьянова, Т. К. Исследование усадки древесины дуба в зависимости от режима сушки : специальность 05.21.00 «Технология, машины и оборудование лесозаготовок, лесного хозяйства, деревопереработки и химической переработки биомассы дерева» : автореф. дис. ... канд. техн. наук / Курьянова Татьяна Казимировна. - Москва, 1981. - 24 с.

10. Sargent, R. Evaluating dimensional stability in solid wood: a review of current practice / R. Sargent // J. Wood Sci. - 2019. - No. 65. - P. 36. - DOI: https://doi.org/10.1186/s10086-019-1817-1.

11. Relationships of anatomical characteristics versus shrinkage and collapse properties in plantation-grown eucalypt wood from China / Y. Wu, K. Hayashi, Y. Liu [et al.] // J. Wood. Sci. - 2006. - No. 52. - P. 187-194. - DOI: https://doi.org/10.1007/s10086-005-0751-6.

12. Effect of cross-sectional dimensions on bow and surface checking of sugi (Cryptomeria japonica) boxedheart square timber dried by conventional kiln drying / K. Yamashita, Y. Hirakawa, S. Saito [et al.] // J. Wood Sci. 2014. - No. 60. - P. 1-11. - DOI: https://doi.org/10.1007/s10086-013-1380-0.

13. Курьянова, Т. К. Коэффициенты влагопроводности древесины дуба мореного / Т. К. Курьянова, В. В. Воронин, А. Д. Платонов // Строение, свойства и качество древесины. II Междунар. симпозиум. - Москва, 1996. - C. 61-62.

14. Петруша, А. К. Технологические свойства мореного дуба и его промышленное использование / А. К. Петрушев // Сборник научных трудов. - Минск : БТИ, 1948. - С. 11-37.

15. Уголев, Б. Н. Определение физико-механических свойств топляковой древесины / Б. Н. Уголев, Я. Н. Станко, Л. В. Поповкина // Деревообрабатывающая промышленность. - 1994. - № 4. - С. 21-22.

16. Физико-механические и технологические свойства древесины. Отчет о научно-исследовательской работе по госбюджету кафедры древесиноведения за 1991 год. - Воронеж : ВЛТИ, 1991. - С. 6-12.

17. Физико-механические и технологические свойства древесины. Отчет о научно-исследовательской работе по госбюджету кафедры древесиноведения за 1992 год. - Воронеж : ВЛТИ, 1992. - С. 6-13.

18. Даниленко, А. Ю. Диэлектрические свойства древесины мореного дуба : специальность 05.21.05 «Технология и оборудование деревообрабатывающих производств, древесиноведение» : дис. ... канд. техн. наук : защищена 24.12.1998 / Даниленко Александр Юрьевич. - Воронеж : ВГЛТА, 1998. - 155 с.

\section{References}

1. Razrabotka uproshchennoj tekhnologii hraneniya kruglyaka i atmosfernoj sushki pilomaterialov morenogo duba. Otchet po NIR. Moscow: NPP «Senezh», 1985. 48 p. (in Russian).

2. Kachalov A.A. Derev'ya i kustarniki [Trees and bushes] / ed. by prof. A.I. Kolesnikov. Moscow: Lesnaya promyshlennost', 1970, 408 p. (in Russian).

3. Jang E., Kang C. (2019). Changes in gas permeability and pore structure of wood under heat treating temperature conditions. J. Wood Sci., 65, p. 37. DOI: https://doi.org/10.1186/s10086-019-1815-3. 
4. Pat. № 2009703 Rossijskaya Federaciya, МПКㄱ 5 B 01 D 53/34. Sposob sushki drevesiny duba morenogo. Kur'yanova T.K., Platonov A.D., Tihonov N.K., Zyuzin A.V., Aralova O.V. zayavitel' i patentoobladatel' OOO NPF "Inno Tekh". № 2007124993/06 ; zayavl. 02.07.2007 ; opubl. 27.03.2009. 4 p. (in Russian).

5. Platonov A.D. Intensifikaciya processa sushki drevesiny trudnosohnushchih porod : dis. ... d-ra tekhn. nauk [DSc thesis].Voronezh: VGLTA, 2007. 280 p. (in Russian).

6. Kang W., Lee N. (2004). Relationship between radial variations in shrinkage and drying defects of tree disks. J. Wood Sci., 50, pp. 209-216. DOI: https://doi.org/10.1007/s10086-003-0559-1.

7. Yamashita K., Hirakawa Y., Nakatani H. (et al.) (2009) Longitudinal shrinkage variations within trees of sugi (Cryptomeria japonica) cultivars. J. Wood Sci., 55, pp. 1-7. DOI: https://doi.org/10.1007/s10086-008-0987-z.

8. Kollman F. Technologie des holses und der Terlin erkstoff. Berlin, 1955. $1183 \mathrm{p}$.

9. Kuryanova T.K. Issledovanie usadki drevesiny duba v zavisimosti ot rezhima sushki : avtoref. dis. ... kand. tekhn. nauk [PhD thesis abstr.]. M., 1981, 24 p. (in Russian).

10. Sargent R. (2019) Evaluating dimensional stability in solid wood: a review of current practice. J. Wood Sci., 65, p. 36. DOI: https://doi.org/10.1186/s10086-019-1817-1.

11. Wu Y., Hayashi K., Liu Y. (et al.) (2006) Relationships of anatomical characteristics versus shrinkage and collapse properties in plantation-grown eucalypt wood from China. J. Wood Sci., 52, pp. 187-194. DOI: https://doi.org/10.1007/s10086-005-0751-6.

12. Yamashita, K., Hirakawa, Y., Saito, S. (et al.) (2014) Effect of cross-sectional dimensions on bow and surface checking of sugi (Cryptomeria japonica) boxed-heart square timber dried by conventional kiln drying. J. Wood Sci., 60, pp. 1-11. DOI: https://doi.org/10.1007/s10086-013-1380-0.

13. Kuryanova T.K., Voronin V.V., Platonov A.D. Koefficienty vlagoprovodnosti drevesiny duba morenogo. Stroenie, svojstva i kachestvo drevesiny. II Mezhdunar. simpozium. Moscow, 1996, pp. $61-62$ (in Russian).

14. Petrusha A.K. Tekhnologicheskie svojstva morenogo duba i ego promyshlennoe ispol'zovanie. Sbornik nauchnykh trudov [Technological characteristics of the fumed oak and its industrial use: selected works]. - Minsk: BTI, 1948, pp. 11-37 (in Russian).

15. Ugolev B.N., Stanko Ya.N., Popovkina L.V. (1994) Opredelenie fiziko-mekhanicheskikh svojstv toplyakovoj drevesiny. Derevoobrabatyvayushchaya promyshlennost' [Woodworking Industry], № 4, pp. 21-22 (in Russian).

16. Fiziko-mekhanicheskie i tekhnologicheskie svojstva drevesiny: Otchet o nauchno-issledovatel'skoj rabote po gosbyudzhetu kafedry drevesinovedeniya za 1991 god [1991 Scientific report]. Voronezh: VLTI, 1991, pp. 6-12 (in Russian).

17. Fiziko-mekhanicheskie i tekhnologicheskie svojstva drevesiny. Otchet o nauchno-issledovatel'skoj rabote po gosbyudzhetu kafedry drevesinovedeniya za 1992 god [1992 Scientific report]. Voronezh: VLTI, 1992, pp. 6-13 (in Russian).

18. Danilenko A.Yu. Dielektricheskie svojstva drevesiny morenogo duba: dis... kand tekhn. nauk [Dielectric characteristics of fumed oak wood: PhD thesis]. Voronezh: VGLTA, 1998. 155 p. (in Russian).

\section{Сведения об авторах}

Курьянова Татьяна Казимировна - кандидат технических наук, доцент, доцент кафедры древесиноведения ФГБОУ ВО «Воронежский государственный лесотехнический университет имени Г.Ф. Морозова», г. Воронеж, Российская Федерация; e-mail: vgltawood@yandex.ru.

Тарасов Анатолий Алексеевич - директор ФГБУ «Воронежский государственный природный биосферный заповедник имени В.М. Пескова», г. Воронеж, Российская Федерация; e-mail: zapovednikvrn@mail.ru.

Платонов Алексей Дмитриевич - доктор технических наук, доцент, заведующий кафедрой древесиноведения ФГБОУ ВО «Воронежский государственный лесотехнический университет имени Г.Ф. Морозова», г. Воронеж, Российская Федерация; e-mail: aleksey66@yandex.ru. 
Снегирева Светлана Николаевна - кандидат биологических наук, доцент, доцент кафедры древесиноведения ФГБОУ ВО «Воронежский государственный лесотехнический университет имени Г.Ф. Морозова», г. Воронеж, Российская Федерация; e-mail: vgltawood@yandex.ru.

\section{Information about authors}

Kuryanova Tatyana Kazimirovna - PhD (Engineering), Associate Professor, Associate Professor of the Department of Wood Science, FSBEI HE "Voronezh State University of Forestry and Technologies named after G.F. Morozov", Voronezh, Russian Federation; e-mail: vgltawood@yandex.ru.

Tarasov Anatoly Alekseevich - Head of FSBI Voronezh State Nature Biosphere Reserve named after V.M. Peskov, Voronezh, Russian Federation; e-mail: zapovednikvrn@mail.ru.

Platonov Aleksey Dmitrievich - DSc (Engineering), Associate Professor, Head of the Department of Wood Science, FSBEI HE "Voronezh State University of Forestry and Technologies named after G.F. Morozov", Voronezh, Russian Federation; e-mail: aleksey66@yandex.ru.

Snegireva Svetlana Nikolaevna - PhD (Biology), Associate Professor, Associate Professor of the Department of Wood Science, FSBEI HE "Voronezh State University of Forestry and technologies named after G.F. Morozov", Voronezh, Russian Federation; e-mail: svetka-sneg@yandex.ru. 